\title{
Clownfishes Amphiprion clarkii and A. sandaracinos (Pomacentridae) coexist in the sea anemone Stichodactyla mertensii
}

Received: 27 October 2010/ Accepted: 16 December 2010/Published online: 4 January 2011

(C) Springer-Verlag 2011

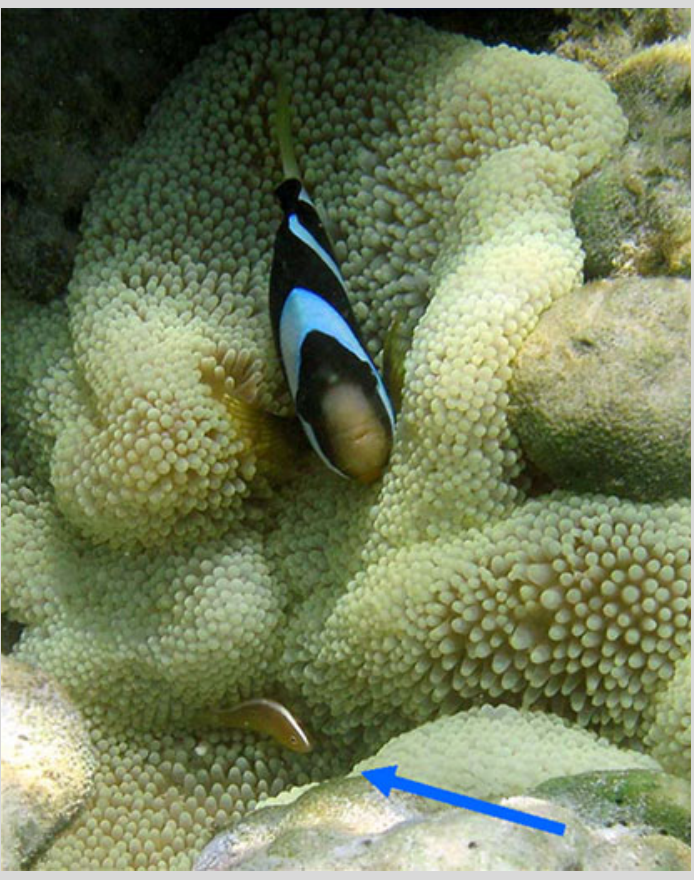

Fig. 1 Amphiprion clarkii and A. sandaracinos (blue arrow) share the sea anemone Stichodactyla mertensii without being aggressive towards one another
Clownfishes (Pomacentridae) are obligate symbionts of sea anemones and usually do not share hosts due to their highly territorial behaviour. Therefore, coexistence of two clownfish species within one host anemone has been considered a rare exception (Fautin 1991) and possible only if fish species divide the host in exclusive territories without sharing space (Fautin and Allen 1992). Coexisting clownfishes, however, always behave aggressively towards one another (Elliott and Mariscal 2001). For example, Amphiprion clarkii (Bennett, 1830) and A. perideraion Bleeker, 1855 coexisted in the anemone Heteractis crispa (Hemprich and Ehrenberg, 1834), where, with intervals of several minutes, $A$. clarkii was aggressive towards A. perideraion (Hattori 2002).

Between July and October 2010, I observed sea anemones occupied by more than one species of clownfish in the Davao Gulf (the Philippines). A specimen of the sea anemone Stichodactyla mertensii Brandt, 1835 (diameter $32 \mathrm{~cm}$ at $1 \mathrm{~m}$ below mean low water) was inhabited by a pair of A. clarkii and three individuals of A. sandaracinos Allen 1972 (Fig. 1). Both A. clarkii specimens had a total length of $10 \mathrm{~cm}$ and those of A. sandaracinos 4, 6 and $7 \mathrm{~cm}$. During 2- to 3-h observation on four occasions, A. clarkii was aggressive towards all fish approaching the anemone, but never towards the A. sandaracinos specimens. Both clownfish species shared their host neither by dividing it into exclusive territories nor by behaving aggressively towards each other. $A$. sandaracinos is highly host-selective and only inhabits $S$. mertensii and $H$. crispa, whereas $A$. clarkii is much less selective and inhabits ten anemone species (Fautin and Allen 1992). During the observation period however, specimens did not move to nearby uninhabited anemones $(H$. crispa), but preferred to coexist in one host. This is the first observation of host sharing among A. clarkii and A. sandaracinos in the sea anemone Stichodactyla mertensii.

\section{References}

Elliott JK, Mariscal RN (2001) Coexistence of nine anemonefish species: differential host and habitat utilization, size and recruitment. Mar Biol 138:23-36

Fautin DG (1991) The anemonefish symbiosis: What is known and what is not. Symbiosis 10:23-46

Fautin DG, Allen GR (1992) Field guide to anemonefishes and their host sea anemones. Western Australian Museum, Perth, p 160

Hattori A (2002) Small and large anemonefishes can coexist using the same patchy resources on a coral reef, before habitat destruction. J Anim Ecol 71:824-831

\section{A. R. Bos $(\bowtie)$}

Research Office, Davao del Norte State College, New Visayas, 8105 Panabo, The Philippines e-mail: arthurrbos@yahoo.com

A. R. Bos

Netherlands Center for Biodiversity Naturalis, P.O. Box 9517, 2300 RA Leiden, The Netherlands

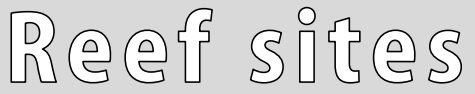

Coral Reefs (2011) 30:369

DOI $10.1007 / \mathrm{s} 00338-010-0713-3$ 